\title{
Study the Nephroprotective Effect of Ziziphus Jujube Extract Against Cisplatin -Induced Nephrotoxicity
}

\author{
Faisal Mohammed Al Tenaiji* and Wael Abdel Aziz Diab Al Zoubi \\ Forensic Medicine and Toxicology, Faculty of Medicine, Jordan
}

Received: 阱 December 26, 2018; Published: 制January 23, 2019

*Corresponding author: Faisal Mohammed AlTenaiji, Forensic Medicine and Toxicology, Faculty of Medicine, Jordan

\begin{abstract}
Nephrotoxicity is a common adverse effect of many chemotherapeutic agents characterized by altered intraglomerular hemodynamics, tubular cell toxicity, inflammation, and thrombotic microangiopathy. Chemotherapy-induced tubular toxicity might be due to decreasing of mitochondrial function, interfering with tubular transport, increasing oxidative stress, and formation of free radicals. Cisplatin is an anticancer agent used largely in treatment of solid tumors. The mainstay dose-limiting toxicity of cisplatin is nephrotoxicity. In this study, we aimed to investigate the protective effects of Ziziphus jujube (ZE), a species of Ziziphus (L) in the buckthorn family Rhamnaceae, on cisplatin-induced nephrotoxicity. Twenty SpragueDawely rats were divided into four groups and received different drug combinations orally. Group I was regarded as control group and received normal saline. Group II received cisplatin at $5 \mathrm{mg} / \mathrm{kg}$, group III received ZE at $500 \mathrm{mg} / \mathrm{kg}$, and group IV received both cisplatin and ZE. All animals were decapitated 6 days after cisplatin administration. Results revealed that cisplatin induced nephrotoxicity as indicated by a significant increase in plasma creatinine and lipid peroxidation. This increase was significantly inhibited in animals pretreated with ZE. Histopathological observations were in correlation with the biochemical parameters in that ZE minimized cisplatin-induced renal tubular damage. Accordingly, ZE provides protection against cisplatin-induced nephrotoxicity in terms of oxidative stress.
\end{abstract}

Keywords: Cisplatin; Ziziphus Jujube; Nephrotoxicity; Antioxidant; Free Radical; Glutathione S-Transferase; Histological Analysis

Abbreviations: ZE: Ziziphus jujube; L: Ziziphus; CIS: Cisplatin Group; GST: Glutathione S-Transferase; Cat: Catalase; MDR: Multidrug Resistant

\section{Introduction}

Cancer is a group of diseases in which cells in the body divide abnormally. The cancerous cells may occur in liquids, as in leukemia or can invade surrounding tissues and spread through the blood and lymph system and establish colonies to other parts of the body. When these cells have migrated to other regions in the body, the cancer is called disseminated or metastasized [1], there are various types of cancer depend on its location, such as lung, colon, breast, skin, ovarian or prostate cancer [2]. Localized cancers can be removed by surgery or irradiation with high survival rates. But, the success of these treatments is frequently limited by metastasis of cancer cells to distant body. So, it necessitates administrating chemotherapeutic drugs to attemptto kill tumor cells throughout the body [3]. Unfortunately, the drugs available for use in chemotherapy are not specific for cancer cells. Most chemotherapeutic agents act either by damaging DNA or by interfering with DNA synthesis. They kill all rabidly dividing cell- not only cancer cells, but also the normal cells that are undergoing cell division [4]. Also, multidrug resistant (MDR) phenotype is a major problem in patients treated with certain natural chemotherapeutic drugs [5].
In general, there are four major classes of drugs which are useful in blocking the synthesis of proteins or enzymes. These are

a) Alkylating agents,

b) The antimetabolites,

c) The steroid hormones, and

d) Miscellaneous compounds with specific blocking effects.

Alkylating agents are the largest group of DNA- damaging drugs, which react chemically with DNA molecules, such as cyclophosphamide, melphalan and mechlorethamine [3]. Cisplatin (cis-diamine-dichloroplatinum) is a nonclassical alkylating agent having the broadest range of clinical activity and the most substantial toxicity profile. Cisplatin-based therapy is curative in testicular cancer and is very active in gynecologic cancer, gastrointestinal malignancies, bladder, head and neck, oesophageal, small cell lung and ovarian cancers [5,6]. It has a harmful side effect profile including nephrotoxicity and ototoxicity $[7,8]$. These 
side effects were primarily mediated by the generation of reactive oxygen species [9].

Cisplatin is one of the most potent chemotherapy drugs widely used for cancer treatment. The discovery of cisplatin, cis- or CDDP) as an anti-cancer drug in the 1960s opened a new era in cancer treatment [10]. The main dose limiting side effects of cisplatin are gastrointestinal toxicity like nausea vomiting and anorexia also cisplatin introduce ototoxicity which cause loss in sensorial hearing and neurotoxicity which manifest commonly as distal sensory neuropathy last side effects is nevrotoxicity [11]. It is recognized that the prevalence of cisplatin nephrotoxicity is high, occurring in about one-third of patient undergoing cisplatin treatment. Clinically, cisplatin nephrotoxicity is often seen after 10 days of cisplatin administration and is manifested as lower glomerular filtration rate, higher serum creatinine, and reduced serum magnesium and potassium levels [11]. Jujubes are species of the genus Ziziphus (L) belonging to the family Rhamnaceae named after the genus Rhamnus. Commonly it is called Chinese date, Chinese Jujube, Indian cherry and Malay jujube. Other names are annab, badari, bayear, ber, black date, bor, red date, regi, spine date, unnab, vadai, vadar, vagari, zao sidr $[12,13]$.

\section{Study Objectives}

The main objective of the study is to investigate the protective effect of Ziziphus jujube plant in rats with cisplatin-induced nephrotoxicity in an in vivo model.

\section{Methodology}

\section{Experimental Design}

Sprague-Dawely rats, each weighing $150-210 \mathrm{~g}$ and their ages between 8-12 weeks, were obtained from the animal house at Jordan University of Science and Technology. They kept at a constant temperature $\left(22 \pm 1^{\circ} \mathrm{C}\right)$ with a regular $12 \mathrm{~h}$ light and dark cycle with providing diet and water. The rats were randomly divided into four groups, each consisting of five animals. Drug was administered orally using a ball tipped stainless steel gavage attached to a syringe. An individual body weights were obtained for test animals' prior administration daily.

a. Saline-treated control group (NS). Rats were given orally $0.9 \%$ Nacl for 6 days.

b. Ziziphus jujube extract group (ZE). Rats will be administered an orally injection of a Ziziphus jujube extract (500mg/kg) daily for 6 days [14].

c. Cisplatin group (CIS). The single dose of cisplatin is $5 \mathrm{mg} /$ $\mathrm{kg}$ intraperitoneally.

d. Ziziphus jujube extract with cisplatin group (CIS+ZE). Rats will be adminstraed cisplatin just as the cisplatin group, except that they will be administered orally with Ziziphus jujube extract one hour before cisplatin dose. Then will be administrated an orally injection of a Ziziphus jujube extract $(500 \mathrm{mg} / \mathrm{kg}$ ) daily.

\section{Preparation of the Plant Extract}

The fruits of Ziziphus jujube were collected from trees growing in Irbid, collected between September and November of 2012. The plant fruits were botanically identified by Prof. Jamil Lahham (Plant Taxonomist. Department of Biological Science, Faculty of Science, Yarmouk University, Jordan). The fruits were shade dried at 25 ${ }^{\circ} \mathrm{C}$ and the dried fruits of plant were grinded with a blender and dissolved with methanol (analytical grade from sigma chemicals, USA), then filtrated through filter paper. Extract was concentrated under reduced pressure and stored in a desicator until further use.

\section{Sample Collection}

The animals in all groups were scarified in an ether chamber after $48 \mathrm{~h}$ from the last application, after an overnight fast. Blood samples were taken by the intracardiac puncture and collected into the heparin tubes. The samples were centrifuged at 3000rpm for 10 minutes to separate their plasma and then stored at $-18 \llbracket \mathrm{C}$ until used for determination of biochemical test. The two kidneys were removed for each rat. One kidney was placed in 10\% formaldehyde solution for processing to histopathology examination by light microscopy. The other kidney was homogenized with phosphate buffered solution (PH 7.2) to obtain 1: $5(\mathrm{~W} / \mathrm{v})$ homogenate. The latter was analyzed to determine the glutathione reductase activity, glutathione catalase activity, glutathione peroxidase activity, glutathione S-transferase activity and lipid peroxidation.

\section{Results}

\section{Body Weight Changes}

After 24 hours of the last oral administration, no mortality was seen in any of the NS, CIS, CIS+ZE and ZE group. Results in Table 1 indicate an increase in the body weight in the control (NS, ZE) groups and a significant increase in CIS and ZE + CIS groups. Administration of CIS produced a significant decreased $(\mathrm{P}<0.005)$ in the body weight when compared to NS. This was largely prevented by pretreatment with ZE in (CIS+ZE) group.

Table 1: Mean body weight difference (\%).

\begin{tabular}{|c|c|c|c|c|}
\hline Parameter & N S & ZE & CIS & CIS+ZE \\
\hline Body weight difference (\%) & $13.7 \%$ & $5 \%$ & $-9 \%$ & $-1.5 \%$ \\
\hline
\end{tabular}

\section{Histological Analysis}

Hispathological studies (Figure 1) revealed that treatment with NS or ZE (Figures 1a \& 1b) result in normal glomeruli and tubules structures. CIS-treated group (Figure 1c) has glomerular and peritubular congestion, RBC, mass edema and inflammatory cells, vacuolization and necrosis in the proximal tubular epithelial cells which were not observed in normal groups. Pretreatment with ZE (Figure 1d) reduce these changes associated with CIS treatment. 


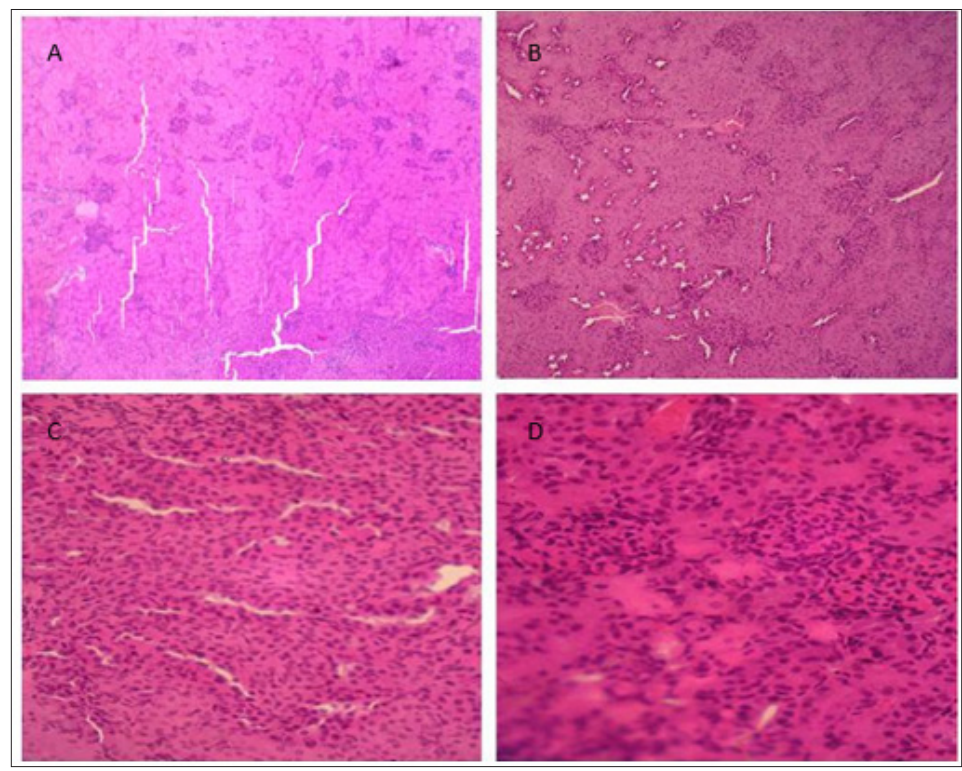

Figure 1: Specimen of kidney showing effects of NS (A), ZE (B), CIS (C), and CIS+ZE (D) (H\&E, X 400).

\section{Biochemical Tests}

Creatinine: Administration of CIS produced a significant increase $(\mathrm{P}>0.005)$ in serum creatinine levels when compared to normal group (NS) indicating nephrotoxicity. Administration of ZE in $(\mathrm{ZE}+\mathrm{CIS})$ group result in a significant decrease $(\mathrm{P}>0.001)$ in serum creatinine compared to CIS group (Table 2).
Serum Urea: Administration of CIS produced a significant increase $(\mathrm{P}>0.005)$ in serum urea levels when compared to normal group (NS) indicating nephrotoxicity. Administration of ZE in $(\mathrm{ZE}+\mathrm{CIS})$ group result in a significant decrease $(\mathrm{P}>0.001)$ in serum urea compared to CIS group (Table 2).

Table 2: The effects of each group in Serum creatinine and urea levels.

\begin{tabular}{|c|c|c|c|c|}
\hline Parameters & Control NS & ZE & CIS & ZE + CIS \\
\hline Creatinine $(\mathrm{mmol} / \mathrm{l})$ & $15.635 \pm 2.405$ & $12.027 \pm 2.404$ & $228.5 \pm 14.779^{\mathrm{a}}$ & $33.375 \pm 11.059^{\mathrm{b}}$ \\
\hline Urea $(\mathrm{mmol} / \mathrm{l})$ & $20.285 \pm 0.591$ & $28.156 \pm 3.789$ & $107.722 \pm 9.958^{\mathrm{a}}$ & $27.851 \pm 3.691^{\mathrm{b}}$ \\
\hline
\end{tabular}

Note: Significant at a=0.05; a: Significant when compared with NS control group; b: Significant when compared with CIS group.

\section{Activities of Antioxidant Enzymes}

The activities of different antioxidant enzymes have been measured in all experiment groups.

Glutathione S-Transferase (GST): In rats treated with CIS, GST activity found to be lower than in NS group. GST activity was significantly increased $(\mathrm{P}<0.005)$ by pretreatment with $\mathrm{ZE}$ in (CIS+ZE) group (Table 3).

Catalase (Cat): In rats treated with CIS, Cat activity found to be lower than that in NS group. Cat activity was increased but non significantly by pretreatment with ZE in (CIS+ZE) group (Table 3).

Table 3: Mean values of Glutathione S-transferase (GST) and Catalase (Cat).

\begin{tabular}{|c|c|c|c|c|}
\hline Parameters & NS & ZE & CIS & CIS+ ZE \\
\hline Cat $(\mathrm{mmol} / \mathrm{l})$ & $864.53 \pm 113.49$ & $846.77 \pm 102.06$ & $294.66 \pm 177.82$ & $453.39 \pm 91.48$ \\
\hline GST $(\mathrm{mmol} / \mathrm{l})$ & $0.395 \pm 0.174$ & $0.906 \pm 0.097$ & $0.218 \pm 0.068$ & $0.625 \pm 0.067^{\mathrm{b}}$ \\
\hline
\end{tabular}

Note: Significant at a=0.05; a: Significant when compared with NS group; b: Compared with CIS group.

\section{Lipid Peroxidation}

Malondialdehyde (MDA) levels in the CIS-treated animals were significant higher than those in the control group. Pretreatment with ZE in (CIS+ZE) group reduced these increases (Table 4).

Table 4: The average mean values of the specific activities of lipid peroxidation (MDA) for each experimental group.

\begin{tabular}{|c|c|c|c|c|}
\hline Parameter & Control (NS) & ZE & CIS & ZE+CIS \\
\hline MDA (mmol/mg protein) & $0.006 \pm 0.003$ & $0.007 \pm 0.002$ & $0.0115 \pm 0.002^{\mathrm{a}}$ & $0.008 \pm 0.002$ \\
\hline
\end{tabular}

Note: Significant at $a=0.05$ a: Significant when compared with NS group; b: Compared with CIS group. 


\section{Discussion}

In the present study, we showed that administration of cisplatin in rats resulted in perturbation of renal function as indicated by a significant increase in plasma levels of creatinine. This result is consistent with the previous studies performed on cisplatin induced nephrotoxicity in both experimental animals and human being [15]. Pretreatment of animals with ZE significantly reduced the increase in creatinine levels. These findings revealed that ZE has a protective potential on cisplatin-induced nephrotoxicity. It has been shown that chemotherapy-induced nephrotoxicity is largely mediated by lipid peroxidation. The later was found to be well correlated with depletion of GSH and impaired antioxidant defense modalities [16]. Measurement of MDA has been utilized as an indicator of lipid peroxidation $[17,18]$. In here, levels of MDA were significantly increased in cisplatin-treated group compared to those of saline group. In parallel, GSH was critically depleted in cisplatin-treated group. This oxidative stress induced by cisplatin might be due to decreased cellular Co-A, acetyl-CoA content and cellular ATP levels [19], or increased lactate dehydrogenase [20].

Previous studies indicate an important role of ROS in the development of nephrotoxicity by cisplatin [9,21]. Cisplatin induced free radical production causing oxidative renal damage. Results in the present study indicated that ZE significantly reduced MDA concentration in kidney tissue. This is probably due to free radicals scavenging and antioxidant properties of ZE. Glutathione S-transferase is believed to facilitate conjugation of GSH with free radicals leading to formation of thioether bond masking their reactivity. It functions as a scavenger of ROS, including hydroxyl radicals, single oxygen, nitric oxide and peroxynitrite [22]. Data of our study indicate that GSH increased when animals received ZE. Animals in the CIS group showed a significant loss in body weights. This reduction in body weight is attributed to reduced food intake and inhibition of protein synthesis induced by CIS. This is a welldescribed side effect in patients treated with chemotherapy [3], and was also reported in cisplatin-treated rats due to inhibition of appetite $[9,11]$.

\section{Conclusion}

We conclude, based on our biochemical findings and histopathological evidence, that administration of ZE minimizes the nephrotoxic effects of cisplatin. Consequently, ZE should be considered as an important potential candidate in clinical trials designed to minimize cisplatin-induced nephrotoxicity.

\section{References}

1. Rashed KN (2014) Medicinal Plants as a Safe Target for Treatment of Cancer. Nat Prod Chem Res 2: e106.

2. Fearon ER, Vogelstein BA (1990) Genetic model for colorectal tumorigensis. Cell 61(5): 759-767.

3. Hellman Samuel, Roswnberg Steven, Devita Vincent (2008) Cancer principles \& practice of oncology. Lippincottv, Philadelphia.
4. Holzgrabe U, Wawer I, Diehl B (2008) NMR Spectroscopy in pharmaceutical Analysis. In Holzgrabe U, Wawer I, Diehl B (Eds.), (1 ${ }^{\text {st }}$ edn.), Elsevier Science Ltd, Netherlands.

5. Pagliuca, C (2008) Synthesis and development of new molecules for targeted tumor diagnosis and therapy. Indian Medicinal Plants, pp. 593.

6. Cepeda Victoria A, Migue Fuertes, Carlos Alonso, Josefina Castilla (2007) Biochemical Mechanisms of Cisplatin Cytotoxicity . Anti-Cancer Agents in Medicinal Chemistry 7(1): 3-18.

7. Ekborn A, Lindberg A, Laurell G, Wallin I, Eksborg S Ehrsson H (2003) Ototoxicity, nephrotoxicity and pharmacokinetics of cisplatin and its monohydrated complex in the guinea pig. Cancer, Chemother. Pharmacol 51(1): 36-42.

8. Xin Yon, Kessarin Panichpisal, Neil Kurtzman, Kennenth Nugent (2007) Cisplatin Nephrotoxicity: A Review. Sciences The American Journal of the medical Sciences 324(2): 115-124.

9. Komala N (2010) Pharmacological evaluation of zizuphas muritiana for in vitro antioxicant, anti-inflammatory and nephroprotective activity. master letter rajivi. Gandhi university.

10. Mckenzie G, Porter T (2001) Clinical Companion:Medical-Surgical Nursing. In Mckenzie G, Porter T (Eds.), (2 ${ }^{\text {nd }}$ edn.), Australia lippy Houston, USA.

11. Ekborn (2003) Cisplatin induced toxicity pharmcokintics. prediction and prevention. Karolinska instate, Sweden.

12. (2001) World Health Organization (WHO) Monographs on selected medicinal plants.

13. Abeer M Waggas, Reem H Al Hasani (2009) Effect of Sidr (Zizyphus spinachristi) Fruit Extract on the Central Nervous System in Male Albino Rats. American-Eurasian Journal of Scientific Research 4(4): 263-267.

14. Prasanna Kumar S, SM Basheeruddin Asdaq, N Prem Kumar, M Asad, DK Khajuria (2009) Protective Effect of Zizyphus Jujuba Fruit Extract Against Paracetamol and Thioacetamide Induced Hepatic Damage In Rats. The Internet Journal of Pharmacology 1: 1531-2976.

15. Pabla N, Dong Z (2008) Cisplatin nephrotoxicity: Mechanisms and renoprotective strategies. Medical College of Georgia USA 73(9): 9941007.

16. Mansour MA, EL Kashef HA, AL Shabana OA (1999) Effect of captopril on doxorubicin - induced nephrotoxicity in normal rats .Pharmacol Res 39 (3): 233-237.

17. Esterbauer H, Schaur RJ, Zollner H (1991) Chemistry and biochemistry of 4-hydroxynonenal, malonaldehyde and related aldehydes. Free Radic Biol Med 11: 81-128.

18. Srour MA, Bilto YY, Juma M, Irhimeh MR (2000) Exposure of human erythrocytes to oxygen radicals causes loss of deformability, increased osmotic fragility, lipid peroxidationand protein degradation. Clin Hemorheol Microcircul 23(1): 13-21.

19. Jez JM, Cahoon RE (2004) Kinetic mechanism of glutathione synthetase from Arabidopsis thaliana. J Biol Chem 279(41): 42726-42731.

20. Dubourg L, Michoudet C, Cochat P, Baverel G (2001) Human kidney tubules detoxify chloroacetaldehyde, a presumed nephrotoxic metabolite of ifosfamide. J Am Soc Nephrol 12(8): 1615-1623.

21. Uchida K (2003) 4-Hydroxy-2-nonenal: a product and mediator of oxidative stress. Prog Lipid Res 42(4): 318-343.

22. Gutteridge JMB (1989) Iron toxicity and oxygen radicals. Baillieres Clin Haematol 2(2): 195-256. 
ISSN: 2574-1241

DOI: $10.26717 / B J S T R .2019 .13 .002413$

Faisal Mohammed AlTenaiji. Biomed J Sci \& Tech Res

cC) (P) This work is licensed under Creative

Submission Link: https://biomedres.us/submit-manuscript.php

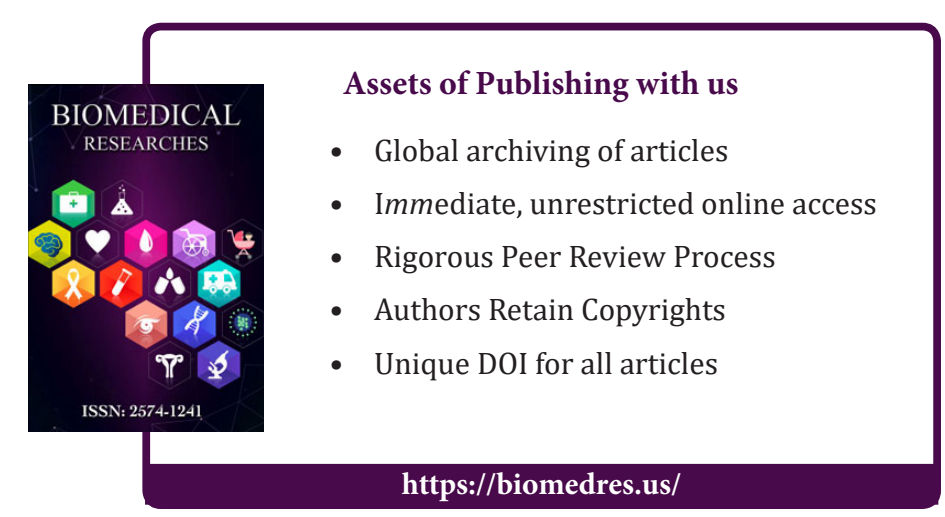

